\title{
Secondary school music education: A case study in adapting to ICT resource limitations
}

Renée Crawford Monash University

\begin{abstract}
This article explores the current availability and use of information communication and technology (ICT) for music education purposes, and music technology resources and facilities, in Victorian government secondary schools. Survey data is presented providing a snapshot of the status of computer and technology resources in government secondary schools in several Metropolitan Regions. Discussion is focused on a case study into one particular secondary school and the perceptions of one music teacher and her students regarding class music and ICT. While preferential treatment for resources, particularly access to ICT, was accorded to some disciplines, arts subjects such as music were frequently excluded. Results indicated that reforming music education to reflect contemporary music practice will not only engage student interest, but also assist in raising the status of music in the school curriculum by demonstrating its relevancy. An effective use of ICT and music technology can assist in emulating real life or authentic learning contexts to achieve this pedagogical change. However, a major challenge illustrated in this case study was the paucity of resources, a concern shared by many music educators. Nevertheless, the music teacher in this case study used the minimal resources at her disposal effectively, providing an exemplar of adapting to ICT resource limitations.
\end{abstract}

\section{Introduction}

High on the recent agenda for the Ministerial Council on Education, Employment, Training and Youth Affairs (MCEETYA) and the Ministerial Council for Vocational and Technical Education (MCVTE) is an implementation of the 'Digital Education Revolution'. Ministers strongly supported this revolution as:
A key strategic tool in achieving a revolutionary improvement in Australia's education and training to world class standards... widespread access to, and effective use of, ICT in Australia's education and training sectors has the capacity to create opportunities to transform learning and teaching environments that can improve education outcomes and increase social and economic participation across Australia (MCEETYA/MCVTE, 2008).

Through the contemporary application of information and communications technology (ICT) in education, pedagogy can reflect current and possible future societal expectations and requirements. Such teaching and learning can use ICT to engage students in authentic learning practices. However, the National Review of School Music Education stated that:

While there are examples of excellent music education in schools, many Australian students miss out on effective music education because of the lack of equity of access; lack of quality of provision; and, the poor status of music in many schools (Department of Education, Science and Training, [DEST] 2005:v). 
This study investigated the current situation concerning technology and resources in Victorian government secondary schools with a focus on music education, and found a dismal lack of resources, supporting the comments made in the National Review of School Music Education. Further, a survey conducted for this study indicated that there was a preferential distribution of resources towards subjects outside the Arts discipline. Given such results, a school with technology limitations and unequal distribution of resources across the curriculum was selected for a single case study. The purpose for this was to explore a very common scenario faced by many music educators. These teachers ask the vital question: How does one incorporate technology in the music program to enhance learning outcomes, but with few resources or time allocation in the computer laboratory?

This study will demonstrate that even with resource limitations, educators can deliver effective and relevant music programs that engage students if the pedagogy supports authentic teaching and learning contexts. Thus the teacher's role becomes particularly significant, "Teachers are vital to the quality of music education for all students and need to take pro-active roles in ensuring the quality and status of music in schools through developing their own professional expertise, learning and values" (DEST, 2005:vi-vii). Results indicated that if technology was used in a past model of schooling the value in using it was lost. However, if the pedagogy was changed to support authentic contexts, students were more engaged and interested in the subject content. Scarce resources and technology should not be used mainly for exercising basic level technology skills, such as word processing, and should be more available for new skills, as in making music.

This article will focus on adapting to ICT resources limitations, a topic drawn from an ethnographic study based on implementing an authentic learning model (Crawford, 2007). Firstly, I consider issues about technology and resources at both Victorian state and local school levels, and discuss relevant ICT initiatives by the Australian Government. Authentic learning will also be discussed briefly, as pedagogical change was identified as a solution to maximise the outcomes from the minimal resources and technology that music educators may have for their classrooms. Concepts and definitions used throughout the article will be clarified before a brief methodology summary. The survey provides contextual information about computer and technology resources available in Victorian government secondary schools and music education. Results from semi-structured interviews and student journal data emphasise the issues surrounding resources and highlight the importance of effective pedagogy. While this study is situated in Victoria, a state in Australia, the discussion may be relevant to other educational contexts as resources and technology in education are issues common to other subject areas and educational settings.

\section{Computers and music technology in music education}

It has been over twenty years since the widespread introduction of computers and technology in schools in Western educational systems (Elliott, 2004). However, many issues about access, cost, training and quality require further effort. Even the popular press recognises the significance of such issues, for example Elliott (2004) wrote that "Most schools would probably say they don't have enough computers, that teachers need more training to use them effectively, and students have more information and communication technology (ICT) expertise than many teachers." 
At this point we need to distinguish between general technology and music technology in the context of this study. There can be a fine line between technology and music technology as computers are used to run many kinds of music technology software. While general ICT can be considered computers and the Internet, for the purpose of this study when music technology is referred to, it includes: computers (containing music software such as Protools, Garage Band and Sibelius), synthesisers ${ }^{1}$, MIDI (Musical Instrument Digital Interface), drum machines ${ }^{2}$, sound modules, MP3 players and minidisk players. It does not encompass keyboards (electronic pianos) or more conventional instruments, though such instruments have contributed much to the foundations of contemporary music technology.

In the current environment of rapid technological change, the Victorian government is recommending a focus on the educational and training needs of local industries with specific skill requirements. This focus is extended to music education and the demands of contemporary music and the changes in the music industry. Due to the importance of technology in the foreseeable future, the Victorian government is ensuring greater access to innovative education and training options across all levels of education and training systems to develop specialist ICT skills and entrepreneurship: "The Government will ensure that all students, teachers and trainers have proper access to computers and learning technologies" (Victorian Government, 2000:14). The Australian Government's commitment to the 'Digital Education Revolution' now totals “\$1.2 billion over five years to 2011-2012" (Australian Government, 2008), including:

\$200 million provided to extend the National School Computer Fund beyond the initial four-year period, ensuring the Australian school system remains at the forefront of educational and technological innovation... In ensuring that young people can make a critical contribution to the nation's future prosperity and international competitiveness, it is vital that measures be put in place to support their inclusion in society, their learning and skill development, and their transition to full participation in a dynamic global labour market throughout life (Australian Government, 2008).

The emphasis that government and education authorities have placed on technology in education for the future of our society, economic growth and placing Australian within a global context is undeniable. The Australian Government declares this technological investment in education as, "an important step in giving all children the skills needed to fulfil their potential, and actively participate in an increasingly global society" (2008). Despite all of these assertions, it appears that even if the schools did have the resources, there was little impact on the teaching and learning of music education.

An immediate priority in improving and sustaining the quality and status of school music was identified by the NRSME as "supportive principals and school leadership, adequately educated specialist teachers, increased time in the timetable, adequate facilities and equipment" (Department of Education, Science and Training, 2005:v). The recommended actions to ensure provision of the facilities and equipment for every Australian student to participate and engage in continuous, sequential, developmental music education programs are as follows:

\footnotetext{
${ }^{1}$ An electronic musical instrument that supports microchip technology, developed in the 1920s and capable of emulating a varied and realistic range of sounds.

${ }^{2}$ The decision was made to include such music technology as a drum machine, but not an electronic piano based on the fact that you cannot program an electronic piano. A drum machine will allow for several layers of programmable sequences.
} 
The Australian Government in partnership:

R. 11.1 Stimulate music education through the provision of one-off grants to Schools for music facilities and equipment, including instruments.

State and Territory school systems and sectors:

R. 11.2 Ensure that schools have up-to-date and well-maintained facilities and equipment to support contemporary music programmes.

Communities and parents:

R. 11.3 Support music in schools through fundraising and advocating for funds, facilities and equipment (DEST, 2005:xxi).

Another key priority identified by the NRSME was to improve curriculum support services that include music technology. Technology not only performs many common tasks, but also has given people the ability to think in new and creative ways. Thirty years ago Attali (1977: xx) foresaw that "a new music is on the rise, one that can neither be expressed nor understood using the old tools". The importance of technology in music has meant its necessary inclusion in teaching and learning. Acknowledging this, a key recommended action from the NRSME was to ensure that music technology is actively included in the curriculum:

State and Territory schools system and sectors:

R. 10.1 Provide and maintain music technology equipment.

R. 10.2 Embed technology in curriculum, syllabi and provide support materials.

R. 10.3 Provide professional development for all music teachers to ensure familiarity and integration of music technology in music programmes.

R. 10.4 Monitor and account for the inclusion of music technology.

Schools and Teachers:

R. 10.6 Incorporate music technology in their programme and account for its inclusion.

R. 10.7 Undertake professional development programmes to develop and maintain their understanding of music technology...

R. 10.8 Demonstrate their capacity to use music technology and integrate it into their programmes (DEST, 2005:xxi).

For teachers to include technology in their teaching, resources need to be accessible and maintained, appropriate technological support provided and professional development encouraged. However, an intermediate solution for extracting the most effective outcomes from the limited resources and technology that teachers have, is to explore a change in pedagogy.

\section{Pedagogical change: Authentic teaching and learning contexts}

According to Gardner, many students do not actually understand or find meaning in what they learn. To some, education becomes nothing more than drill and practice or drill and response to routine tasks without relevance for the materials that students are expected to learn (Gardner, 1991). Psychologists such as Piaget (1954, 1974) believed that the learner must be active to be engaged in real learning. Active learning is regarded as the ability to connect new knowledge with prior understanding. Constructivists take this notion further by explaining that the learning environment should contain a meaningful context, one that brings the real world into the classroom (Brown, Collins \& Duguid, 1989). Traditional learning situations in which students are passive recipients of knowledge are inconsistent with the learning situations that occur in real life (Lave, 1988). Therefore, in order to make student learning relevant to real life experiences, learning environments call for pedagogical change and reformation. 
The suggestion that is implied in this study is one that considers authentic learning and teaching contexts.

If learning is authentic, students should be engaged in genuine learning problems or tasks that foster the opportunity for them to make connections between new material and prior knowledge. The Teaching with Technology Initiative (2003) discusses the relevance of authentic learning:

When learning activities are authentic, students see the significance of what they are learning because the tasks mirror real-life experiences - activities that personally relate to students and their world. Students explore, discover, discuss and construct concepts that involve their world. They learn to think critically, analyze information,

communicate ideas, reach logical conclusions, collaborate with others and create multiple solutions. The true goal of authentic learning is to help students find relevance in their learning and to apply what they have learned in the world.

The notion of authenticity has had a long currency in education, though a detailed discussion is beyond the scope of this article. A current definition of authenticity states that knowledge, whether it be moral or informational, is based on consciousness, experience and reflection (Marra, 2004). This contemporary understanding of authenticity was first introduced in medical education for an improved interface between theoretical academic learning and clinical practical learning (Barrows, 1986). Since, it has been referred to in other areas including music, philosophy, education, art, writing, assessment, motivation and technology (Marra, 2004). Examples of recent studies that utilise technology for authentic learning that reflect similar concepts, but in different subject areas include Herrington and Oliver (2000), Kearney and Schuck (2006), and Brickell and Herrington (2006). Elliott refers to the nature of authentic learning environments in music as 'curriculum-as-practicum' explaining:

\section{Musicianship is a practice-specific and that four or five of its knowledge components are essentially nonverbal and situational. What this means is that musicianship develops only through active music making in circular situations that teachers deliberately design to approximate the salient conditions of genuine musical practices (1995:72).}

Learning occurs for the purpose of inquiry, curiosity and answering questions that arise during encounters with personally meaningful, problem laden events. Learning and the value of such learning is redefined when the questions students seek answers to are their own. Before the results are discussed, a brief methodology summary will assist in understanding the research process.

\section{Research method summary}

This ethnographic research undertaken in 2006-2007, utilised a mixed method approach including various forms of data collection. After an extensive literature review, historical data were collected. A survey was sent out to Victorian government secondary schools to investigate access and equity issues with ICT and music resources. Questions sought insight into the ways technology was perceived and used in teaching, learning and various other school management tasks. From the collated survey data, a single school identified here with the pseudonym 'Ocean Blue Secondary College' was approached for a case study. The case study was conducted with the assistance of school music coordinator identified by the pseudonym 'Ms Phoebe Smith'. This school was selected for this case study because of the 
comparatively poor resources available to the music teacher, the inequality of resources across subjects, and the challenges this then presented the teacher. The survey data indicated this scenario as common in music classrooms across Victorian government secondary schools. The case study was conducted in a poorly resourced music class with a view to demonstrating that, even where unsupported, authentic learning and teaching can achieve rewarding outcomes. This example of adapting to resource limitations to enhance authentic learning may assist other educators in similar circumstances.

An initial, broad ranging semi-structured interview with Ms Smith determined her perceptions about the availability of music resources and technology in the school. This provided insight regarding the difficulties music teachers faced in attaining reasonable requests about and access to the school's facilities. In collaboration, Ms Smith and the researcher designed units of work for years 7 and 8 general music ${ }^{3}$ and years 9 and 10 elective music ${ }^{4}$, that utilised technology to enhance contemporary music practice in what could be considered an authentic way. For this program Ms Smith was able to gain access to an intermediate level computer laboratory. As much of the work was done in small groups, Ms Smith's personal laptop was also used where appropriate. For general music classes these resources were adequate. The years 7 and 8 unit of work explored graphic notation and soundscapes (sound, listening, performance and composition) using technology where possible. The years 9 and 10 unit of work on composition and film music included an excursion to the Alfred Brash Soundhouse $^{5}$ at the Victorian Arts Centre. Given the general paucity of resources at Ocean Blue Secondary College, it was intended that elective music students who are interested in music for further study or a possible career should experience music technology at a professional level. This could give students a realistic understanding of what occurs in the music industry in addition to the opportunity to work with up to date music technology in a music studio. All students were required to complete three journal entries throughout the unit.

The student journals proved to be a rich source of data. The first journal entry occurred at the commencement of the unit to capture initial views on ICT in their music class. The second entry was completed in the middle of the unit to observe changing perceptions and provide a guide for modifications if required. The final entry was made at the end of the unit to compare initial and secondary perceptions, identify links in understanding and recurring themes, explore whether what the student learnt is what the teacher intended, and to give the students a chance to express their views on the value of using technology in music class. The next section discusses the findings of the survey results as a snapshot of the status of computer and technology resources in Victorian government secondary schools.

\footnotetext{
${ }^{3}$ General music is compulsory part of the Victorian arts curriculum for students in Years 7-8, age range $11-13$ years.

${ }^{4}$ Elective music is an optional arts subject that can be taken by students in Years 9-10, age range 13-15 years.

${ }^{5}$ The Alfred Brash SoundHouse opened in 1986 at the Arts Centre in Melbourne, Victoria was the first of its kind. The initial aim was to foster musical creativity through providing access and guidance to music technology. SoundHouse has broadened its scope to include a plethora of music, multimedia and communications technologies. SoundHouse has developed a broad range of curriculum across a number of disciplines, and has established itself as a leader in the field of integrating technology into learning (Intelliware Australian, 2006).
} 


\section{Survey results: Computer and music technology resources}

The results from the 2006 survey are indicative of the technology resources available to school music teachers, and their opinions about utilising technology in music teaching and learning in Victorian government secondary schools. A total of 138 schools, including P-12 secondary schools were approached and 119 schools responded. One music teacher from each school was asked to fill in the survey. The questions coverered general information, contextual information, specific information (selected response) and specific information (open ended). Responses indicated that across all responding government secondary schools in the Northern, Southern and Eastern Metropolitan Regions each school had between 120 and 210 desktop computers. These computers were located mainly in computer laboratories not available to music classes. Only 5\% of schools in these regions had computers located in the schools' music rooms, numbering 27 to 60 computers, with an average of 10 in a computer equipped music classroom. Some schools had none. All teachers who responded indicated that if the computers were available, they would use them for both general and elective music teaching.

Northern, Southern and Eastern Metropolitan government secondary schools had between 0 and 27 synthesisers, the average being two per school. Only 5\% of schools had a computer in the music classroom attached to a synthesiser. While schools have good quality synthesisers, such as Roland, Korg, Yamaha and Casio, they can be quite old. Apart from the schools that have no synthesisers, every school has a Roland, ranging from 5 to 15 years old. This raises the question that some of the synthesisers may be out dated and incompatible with music software if attached to computers. This in turn means that sound libraries available on the instruments are also quite dated. Results indicated that if teachers had access to synthesisers, they would use them for both general and elective music.

In most schools, other music technology included MP3 players, CD players, tape recorders, minidisk players and amplifiers. It is important to note that these lists of technology devices came from the music teachers who completed the survey. Regardless of the definition of music technology for this study given on the survey cover letter and the progress technology has made in contemporary society, there is still a misconception that amplifiers, tape recorders and the like are music technology. As mentioned previously, for the purpose of this study, when music technology or technology in general is referred to, it includes such items as: computers, the Internet, synthesisers, MIDI (Musical Instrument Digital Interface), drum machines, sound modules, MP3 players and minidisk players. Schools that position themselves as having a strong music education program have the music technology that includes MT32 MIDI, digital multi track recorders, Tascam 4 track recorders and PA. All teachers agreed that they tried to utilise these types of music technology where possible in all their music classes. Primary reasons given for its use were because it engaged students and provided an easy way to teach listening and aural skills. An interesting point made by one teacher was that music technology is an integral part of rock music. This teacher considered that students valued 'rock music', thus relating the curriculum content to what they find interesting. Technology is central to the evolution of this style. This is a direct link to both valued knowledge and authentic learning.

Figure 1 summarises survey findings on music teachers' use of computers and the Internet. 


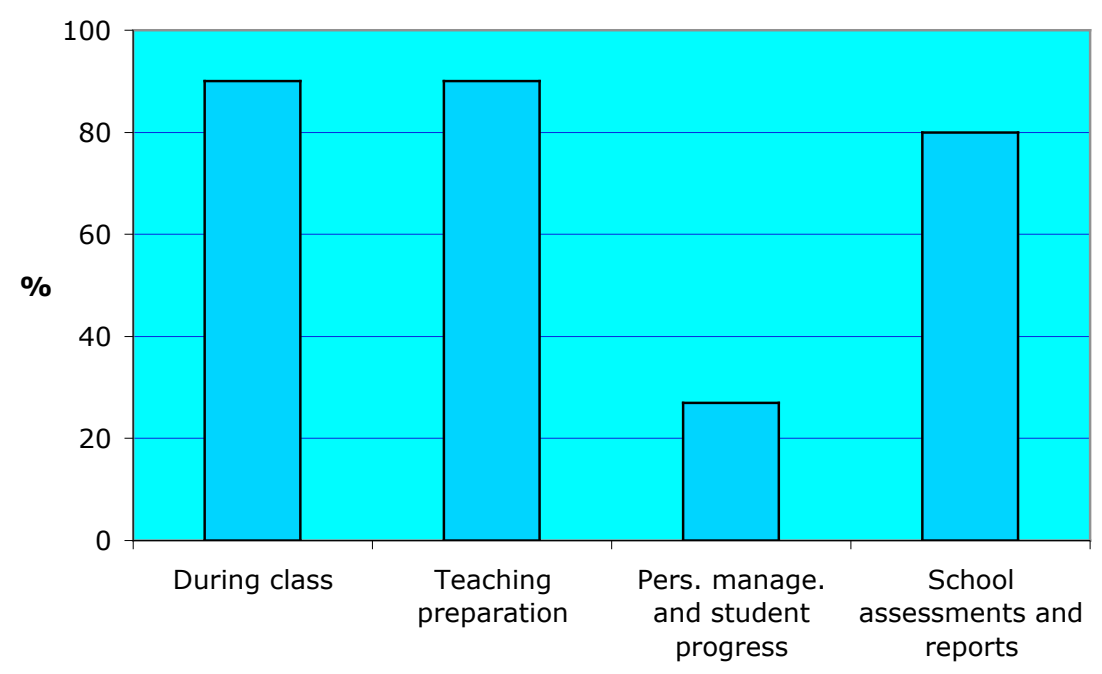

Figure 1: Utilisation of computers and the Internet $(\mathrm{n}=119)$

Results indicated that $90 \%$ of music teachers used computers and the Internet for teaching during class for all the year levels they teach. All teachers agreed that the Internet is very valuable for assignments and research for both themselves and the students. This constitutes using technology for non-musical activities, such as, text based research or assignment presentation. It is reasonable to conclude that this basic use of technology is seen by teachers as fulfilling the requirements set by schools and curricula for the inclusion of ICT in their subject. Schools with reliable computers and music technology resources used music programs for aural training, arranging, notating, transcribing and composing. Computer applications utilised included Microsoft Office (Word and PowerPoint particularly), Microsoft Publisher, CD/DVD cover programs, Sibelius, Acid DJ, Musition, Band in a Box, Music Time, Auralia, Internet Explorer and the Google search engine.

Also highlighted in the survey data was the importance of technology for teachers undertaking administrative tasks, class preparation and other general purposes. The data indicated that $90 \%$ of teachers use computers and the Internet for teaching preparation. Only $27 \%$ of teachers used computers or the Internet outside of class for management and student progress reports. A total of $80 \%$ of teachers used computers and the Internet for completing school assessments and reports. Overall, teachers estimated that $95 \%$ of students in a Victorian government secondary school music class would have access to a computer at home. Due to requirements for utilising ICT in their subject, and because most believed it to be a good learning experience, $90 \%$ of music teachers assigned projects that required their students to use a computer. A total of $75 \%$ of music teachers assigned projects that required their students to use a computer outside the classroom.

Nearly half $(45 \%)$ of music teachers considered themselves only 'somewhat prepared' for using computers and technology, whilst only 35\% considered themselves to be 'well prepared' and only $20 \%$ considered themselves 'very well prepared'. Results indicated that their development of skills in using computers and technology has been largely due to independent learning. Interestingly, $75 \%$ of teachers agreed that college 
or university did not prepare them for using technology for teaching. Overall, it seems that professional development has assisted teachers to only a small extent. Colleagues and students have assisted to a moderate extent. Further, in the five years prior to the survey, $20 \%$ of music teachers had no professional development, $60 \%$ had $1-8$ hours and 20\% had 9-32 hours. Thus the majority of music teachers have had very little professional development in the use of new technologies. It was generally agreed that professional development can be helpful, but only when the skills learnt are practised regularly. Highlighted here is the irrelevancy of such professional development if the school has few or no resources to support the incorporation of new technologies into the teaching and learning of music.

\section{Resources and facilities at Ocean Blue Secondary College}

The data gathered provided a contextual basis for the consideration of one school selected for its poor, but representative provision of technology resources for music classes. The school's technology resources are described in the school charter as having an "excellent student to computer ratio" and that this enables the use of "Learning Technologies across the curriculum" (The School Charter, 2006). As will be seen, the school's stated technology resources are not necessarily a true indication of the current situation for the arts or music curriculum. The school is promoted in the charter and on their website (2006) as presenting an array of excellent resources and educational facilities:

- 350 seat performing arts theatre.

- Four modern strategically located computer laboratories/ networked computer system

- Computers/ internet and email facilities.

- A number of laptop computers are also available for student use.

- The computer laboratories are controlled and maintained by the Information Technology teacher and two additional IT laboratory assistants.

- Instrumental music facilities.

- Excellent technology buildings and equipment.

- Specialised art and visual communication areas.

- Library Resource Centre with an integrated computer network system. (The School Website, 2006).

It is understandable that the school charter and school website are animated and pomotional in their description of the school and its resources. Ocean Blue Secondary College's student numbers have to be maintained in the face of enrolment competition from surrounding schools. The two main points of reference for public access present the school as an innovative and vibrant learning environment offering the best there is in education facilities. However, Ms Phoebe Smith was quite passionate and vocal about the lack of resources in the music department, the unequal distribution of resources throughout the school and across subjects, and the lack of support from level coordinators, vice-principals and the principal.

\section{The teacher's perception of resources and ICT in music education}

The first interview with Ms Smith was a general interview held in June 2006. It was designed to answer broader contextual questions about music education, the use of technology in music education, the status of music at Ocean Blue Secondary College, the resources available, and the support from the school hierarchy. It was established 
early in the interview that music, like other arts subjects at the school, was not given reasonable access to the computer laboratories or shared technology resources.

The school charter placed emphasis on Ocean Blue Secondary College providing students with a complete learning experience through special programs that included the arts and sport:

- Award winning Arts program - participating in the wider community Art Competitions

- Music presentations and performances

- Major annual theatre production

- Successful participation in inter-school sports competitions (The School Website, 2006).

It seems reasonable to suggest that 'Arts' is important to the school as a marketing opportunity appealling to the wider community. However, there appeared to be misunderstanding about the need for technology in the arts subjects. Ms Smith illustrated her view of the difficult situation concerning resources and IT support:

In my school, technology is something I keep pushing for, but because of the lack of support, it is a problem. I'm not getting as much support as I keep getting told that I'm going to be getting. And we have a lot of problems, so for me to even think of asking for a spare 10 year old computer to use, is impossible, it's just absurd. Even with downloading free music programs from the Internet took me a year to eventually get them onto the computers and it was there for a month before they updated the computers and got rid of all of them. They just got rid of them! I said hey I'm happy to take [the computers], but they said "no" and just got rid of all the computers (Smith, 2006).

Although the school may wish to promote IT in all subjects and fulfil the ICT requirements set by the Victorian Government and education authorities, it did not provide much support to their teachers in the arts. Ms Smith explained that the viceprincipals and principal only have a small amount of input into controlling access to the computer rooms. When asked the question whether the principal and viceprincipals are concerned with the lack of technology being used in music Ms Smith said:

Well, they are enthusiastic about the ideas and things I wish to achieve in using technology in the classroom, because they say "we want to get the music up and running!" But when it comes down to it nothing happens because of resources, budget, time, communication between the departments, it just doesn't work and is therefore put in the back of their minds and made less of a priority (Smith, 2006).

While the music teacher is enthusiastic about using technology in her classes and in turn the principal and vice-principal are keen to improve music at the school, the lack of support prevents this from occurring. Other subjects tend to be given precedence over music:

Other subjects have specific timetabled classes in the computer rooms. I can request a period in the computer room for my classes, but the chances are I would end up in a room... where you won't be able to hear anything or it might be a random class where I wouldn't need to use the technology. So you have no control over when you get the period in the computer room. ESL, psychology and various other subjects have set classes in there, so I would just be fighting for time (Smith, 2006). 
It is interesting to note that the school accorded importance to timetabling classes for English as a second language (ESL) in the computer laboratories. Ocean Blue Secondary College is a highly multicultural school, so it is understandable that took measures to use ICT in addressing language and literacy issues.

Issues of professional development and general attitudinal issues towards technology in education appeared in the discussion. While Ms Smith considered herself technologically capable and had embraced technology, there was resistance to the general idea of technology in education from other teachers; they struggle with ICT requirements and its use. Ms Smith elaborated a view:

I consider myself technologically capable. It is how I am; I can quite easily have a discussion with my students about what they have on their Ipods and exchange songs, etc. But for other teachers, it's not the first thing that would come to mind. They won't necessarily suggest cross-curricula topics using ICT, and if they do, they usually end with, "Your part in it will be to write the music out". Whereas I would be, but we could just use computers. And they don't think where this subject could lead to, for example, my student could be an engineer, therefore music engineering would be interesting and engaging. You know, when you're teaching your Head of Arts to use her Mac, you kind of realise why the lack of emphasis in technology in the Arts.

Obviously our generation is different to the previous generation of teachers, before us, but we've got a lot of teachers who just refuse to do anything on computers (Smith, 2006).

The apparent reluctance of older teachers to use technology is understandable to some degree. This might explain why technology, when used by such teachers, is often utilised in a past model of teaching and learning. The question must be asked how open minded and sensitive are teachers to preparing students for knowledge and skills that can equip them for both the present and the future. Implicit in these observations is that students will continue to reject schooling because they are disinterested in both the content and method of what is being taught. Understanding what valued knowledge is in contemporary society and in education is important. Bennett elaborates, "Young people take the cultural resources provided by the popular cultural industries and use the prescribed meanings attached to such resources as templates around which to construct their own forms of meaning and authenticity" (2000:27). There needs to be a balance between what the school considers valued knowledge and the students' understanding of the concept. Only then can music learning with technology be perceived as authentic by the students.

It appears that Ocean Blue Secondary College generally encouraged professional development for teachers. Ms Smith elaborated:

We have one guy in particular who all he does is organise PD for teachers on various programs. Last term he introduced Windows movie maker and was very enthusiastic and promoted it by saying how much the kids will love using it. And it would be a great way to jazz up your assignments. A lot of negative responses to such programs like this one was, “No, you can't use that for maths!" Some teachers don't show up for PDs and the overall attitude is fairly negative (Smith, 2006).

The principal and senior management positions at the school need to encourage ICT in education by providing positive support and emphasising the importance of such professional development. Smith explained her view: 
The principal does announce these things are on, but he doesn't really encourage them as such or insist upon them as, "You should do this". It's voluntary. Particularly when a maths teacher tells him, "I don't have time to do this!" And then he the principal would just be "ok" with a fairly casual attitude. So, it is completely up to us, but it is interesting that it is the same people that do it all the time (Smith, 2006).

Ms Smith concludes that "those teachers reluctant in utilising technology for education are intimidated by it". From the results of the survey and interviews with Ms Smith, it seems that many students are more technologically literate than their teachers. This may be a major factor in the reluctance to use technology. The positive outcomes from the survey results indicated that the majority of music teachers, technologically capable or not, were willing to learn ICT themselves because they understand its importance in education and to music in general.

The current status of technology in Victorian music education surfaced during a discussion about Ms Smith's concern for lack of resources. The Victorian Education Blueprint (2004) highlighted that innovation and technology were to be given consideration in the curriculum across all subjects. The NRSME (2005) also suggested ICT as a recommended inclusion in the music curriculum. Ms Smith's agitation about resource limitation came from an understanding of the importance of technology in music. Her utilisation of technology in teaching and learning was motivated by student engagement and interest and the benefits of immediate musical realisation. Ms Smith explained her view:

Using technology is fun! Because a lot of these kids in years seven and eight have music as a compulsory subject and to actually get them in front of a computer and to compose a piece of music is fantastic. And then to record it onto a CD! They love that, because they've done it, and they did the whole thing. It's their own, that they made up. The majority of these kids don't know anything about music (Smith, 2006).

It is important to note here that Ms Smith was undervaluing what the students do know about music. It is naïve to assume that because students have not undertaken formal music training in the traditional, skill intensive sense, they do not know anything about music. Extensive studies on popular music and culture argue that it is traditional music education that needs to come in line with contemporary times, society and its subsequent musics, particularly if the subject is to engage students (Swanwick, 1968; Vulliamy \& Lee,1980; Johansson \& Miegel, 1992; Reimer, 1995; Bennett, 2000). Ms Smith continued:

When I was at school it was easy for me, for example, to arrange a piece of music, because I could just write it. It would take the whole two years of compulsory music in years seven and eight to get them to be able to write just a simple melody out.

Whereas on these programs, like I have been doing, on my laptop, they [students] are able to write things much quicker. For some kids it's a case of "I like this, this loop goes well with this loop I'll put that together" and before you know it they have a sixteen bar melody (Smith, 2006).

Ms Smith identified the boundaries that traditional music notation posed in learning to write a simple melody. In a compulsory general music situation, allowing students to learn with technology in this way is engaging and interesting because the realisation of their musical efforts is immediate. Computers and technology are devices that students can relate to. Therefore using such media for teaching and learning means that the students will value what they learn and acquire understanding of basic musical concepts, sounds, timbres, time and space and musical structures very quickly. 
Technology allows for innovative ways of expressing music in symbols. The ability to read music in the traditional sense is a skill of symbolic transfer, not an inherent musical skill. Further, it has been asserted that adherence to traditional notation often serves more as a hindrance than a facilitator encouraging creative music making (Vella \& Arthurs, 2000; Vella \& Arthurs, 2003).

Ms Smith extended this idea of using technology for immediate music realisation:

Music is something that is experiential and practical and that makes the practice of it authentic. Therefore, the nature of music and particularly music as a subject makes it authentic.

Thus, just as making music using instruments is considered experiential and practical, creating music using computers or technology can also be regarded in the same light. Engaging students in learning music in a contemporary way makes the practice of music authentic. This aligns with the current Victorian Essential Learning Standards (VELS) that supports student engagement with contemporary knowledge and practice and uses technologies in ways that reflect professional and community practice (Victorian Government, 2007). This becomes particularly significant for compulsory general music classes in which most students have little intensive musical knowledge or skill and technology is a way of engaging those students in the practice of music in an authentic and accessible way.

Governmental and educational authorities have placed technology on priority lists due to its foreseeable innovative benefits (Victorian Government, 2000; NRSME, 2005; Victorian Education Blueprint, 2004). From the assertions these authorities have made, it can be identified that the importance technology will have for the future of our society and contemporary music is significant. It is this reason that the lack of resources and their unequal distribution, lack of school management support, professional development and time management need to be given serious consideration by Ocean Blue Secondary College and other schools which are in similar situations.

Another major issue already identified is that the value of technology in teaching and learning will depend on the way the technology is utilised. It should be used in a contemporary way to support societal expectations and the knowledge and skills necessary for today's music. This is not to disregard past musics, just a case of using an innovative method for an innovative purpose. Further, it is important to consider the extent to which the music students at Ocean Blue Secondary College were aware of the resource issues at their school and discern whether this had any effect on their learning.

\section{Students' perception of resources and ICT at the College}

The student journals provided a rich source of data and entailed three entries over a unit of work that spanned from July 2006 to September 2006. The issue of resources at Ocean Blue Secondary College did appear consistently throughout the student journals in both general and elective music. Across each of the four year levels, $100 \%$ of the 97 respondents thought the lack of resources and unreliable resources were a disadvantage to using technology and computers in music class. The following are examples of the responses the students gave in years 7 and 8 general music: 
At Year 7 level:

Student 1: $\quad$ The computer didn't work properly sometimes.

Student 2: $\quad$ The computers crashed sometimes.

Student 11: $\quad$ They break down in class.

Student 14: $\quad$ Sometimes they break down.

Student 23: $\quad$ Computers don't work sometimes.

At Year 8 level:

Student 3: $\quad$ The computer crashed at times.

Student 6: $\quad$ The computers need to work good because they will break down and freeze.

Student 20: $\quad$ Need reliable technology.

The inadequacy of school resources was highlighted by student awareness of the lack of computers and technology available and their unreliability. An interesting observation was made by a student at year 8 level who responded in the second journal entry that "because the technology is not state of the art", resources have hindered what the student had expected to learn by the middle of the unit. This is correct; the units of work were extended because of resource limitations. One major problem was programs too running slowly or the computers 'freezing' due to older hardware. The expectation from the students was that technology would be innovative and will help them learn more and at a faster pace. This preconception about technology is a direct response to what the students' value because it is what happens at home and is what society has taught them to expect. Students are intuitive about their circumstances and how it affects their own learning. The following disadvantages for using computers and technology in music class are examples from students in years nine and ten:

At Year 9 level:

Student 5: $\quad$ At school computers and technology are not very reliable.

Student 6: At school, computers, technology and instruments are not good to work on at all. They are always breaking down and it is very frustrating.

Student 13: The computers at school crash too much, it's annoying.

At Year 10 level:

Student 3: Our school technology is far from state of the art, it is frustrating when it breaks down.

Student 5: $\quad$ Unfortunately the school technology is not the best and causes heaps of problems sometimes.

It is significant that $100 \%$ of responding students identified the lack of resources and the unreliability of technology at Ocean Blue Secondary College to be a major issue. Many students are technologically literate and if education is to be valued by such students, it must be relevant to the context of current times. Figure 2 represents the percentage of students who have a computer at home across all four year levels.

The high percentages in Figure 2 are significant in that students taking elective music typically can support their interests by using a computer at home. These results also suggest an expectation that students may have about being given a one to one student to computer ratio in class. In response to a question about issues in using computers and technology in the classroom, a year 8 student responded that, "Too many people to have a turn". This student, like many others, was used to working or playing on computers without having to share. In order to overcome the lack of resources in the school the decision was made by the researcher and Ms Smith to arrange the classroom tasks in small groups. This group work also encouraged student centred, self directed 
learning and engaged students in multidimensional, non-linear learning as students could discuss their tasks and make decisions together.

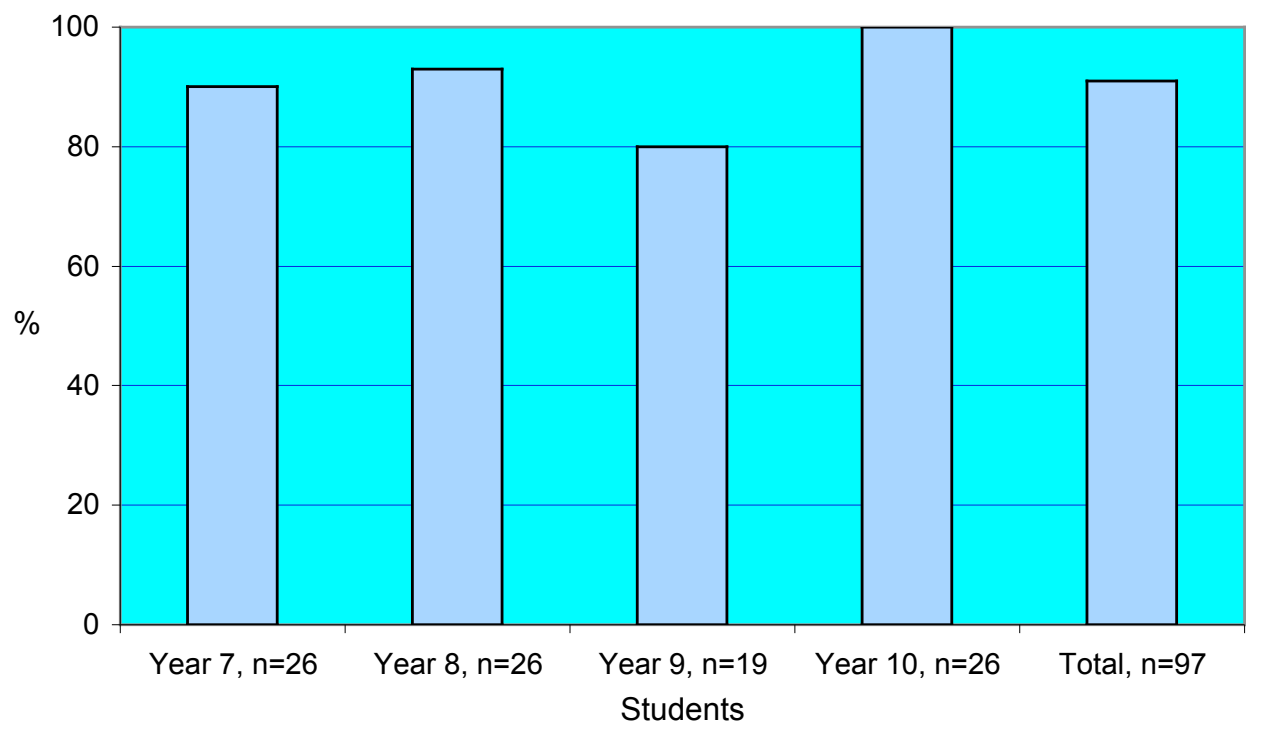

Figure 2: Students who have a computer at home

Figure 3 represents the percentage of students who have access to other music technology at home. This is predominantly in the form of MP3 players such as the Iriver or Ipod, older students tend to extend this to mixing devices and DJ equipment.

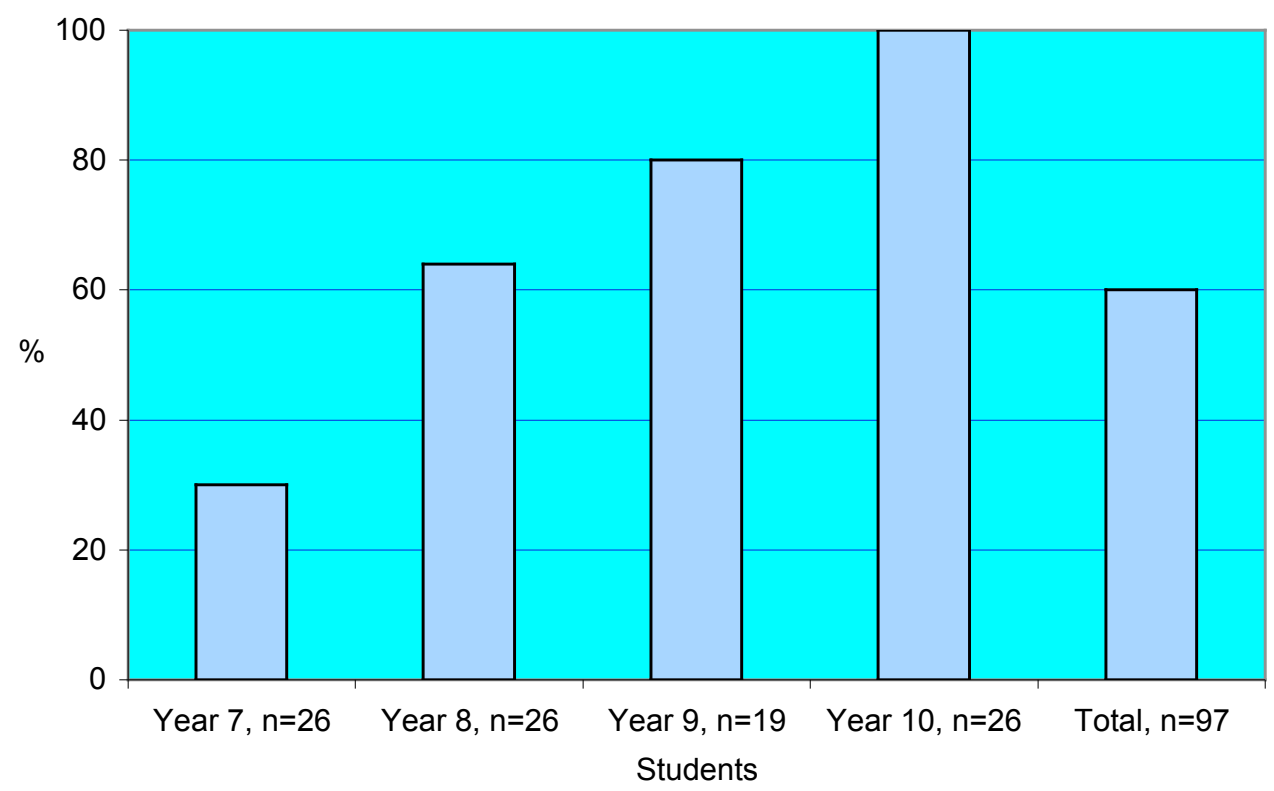

Figure 3: Students who have music technology at home 
The percentage of students who have music technology at home increases each year level with $30 \%$ of responding students at year 7, 64\% at year $8,80 \%$ at year 9 and $100 \%$ at year 10. It is interesting to note that as students' age increases, music technology items seem to become increasingly desirable. This may be due to market saturation, self identification as a musician or other factors.

It was identified that $91 \%$ of responding students have a computer at home, compared to $60 \%$ who have other forms of music technology. Every student who has an MP3 player or music technology also has a computer. Results indicate that students' literacy in computers and technology is increasing and they are noticing the resource issues at their school. Many students appear frustrated with the circumstances and have identified resource issues as a hindrance to their learning.

\section{Conclusion}

The issue of the lack of computer and technology resources has been indicated at national, state and local levels. As stated previously, the 'Digital Education Revolution' announced in the recent Australian Government budget is proof of its commitment to utilising technology in education. The importance of technological innovation for the future is undeniable, and to ensure the prosperity of the nation's educated and skilled workforce technological literacy and competency is essential. Unfortunately, as indicated by the survey data, the poor status of music in schools is noted as a cause for the unequal distribution of resources across subjects. Ms Smith confirmed the extent to which this is a problem. At Ocean Blue Secondary College, it was noted that mangement did not understand fully the requirement in music class of having computers enabled to play back sound. The importance of incorporating computers and technology in the curriculum for contemporary and future society and economic growth has been noted. However, this survey and case study are indicative that while there have been and currently are initiatives by the government and educational authorities in place to assist schools' resource funding, a resolution in the near future is doubtful. It is imperative then, that music educators need to adapt to their current situation and consider pedagogical change.

This study has identified the importance of ICT, the necessity for reliable resources and for music teachers to receive appropriate school support, technical assistance and professional development. For teachers to extract the most from what technology is available, it is important to not use it within traditional teaching and learning contexts. Technology needs to be used in a contemporary way using authentic learning contexts to enhance the subject and allow students the opportunity to develop skills necessary in the contemporary practice of music and society. Therefore, in this case, music teachers need to be taking pro-active roles in ensuring the quality and status of music in schools. Adapting to resource limitations by the effective use of ICT will achieve positive learning outcomes.

\section{Interviews}

Smith, P. (2006). General teacher semi-structured interview. Interviewed by R. Crawford on 11 June 2006. 


\section{References}

Attali, J. (1977). Noise - the political economy of music. Translated by Brian Massumi. Manchester: Manchester University Press.

Australian Government (2008). Ministerial Statements. Budget 2008-09. Education Revolution 20082009. [viewed 21 May 2008, verified at new URL 6 Aug 2009] http:/ / www.budget.gov.au/200809/content/ministerial_statements/html/index_education.htm

Barrows, H. (1986). A taxonomy of problem-based learning methods. Medical Education, 20, 481486.

Bennett, A. (2000). Popular music and youth culture, music identity and place. UK: Macmillan Press.

Brickell, G. \& Herrington, J. (2006). Scaffolding learners in authentic, problem based e-learning environments: The Geography Challenge. Australasian Journal of Educational Technology, 22(4), 531-547. http: / / www.ascilite.org.au/ajet/ajet22/brickell.html

Brown, J. S., Collins, A. \& Duguid, P. (1989). Situated cognition and the culture of learning. Educational Researcher, 18, 32-42.

Crawford, R. M. (2007). Authentic learning and digital technology in the music classroom. Unpublished $\mathrm{PhD}$ thesis, Monash University.

Department of Education, Science and Training (DEST) (2005). National review of school music education. ACT: Australian Government. http:/ / www.dest.gov.au/sectors/school_ education/publications_resources/profiles/school_music_education.htm

Department of Education and Training (2004). Principles of Learning and Teaching P-12. In Blueprint for Government Schools. [viewed 17 Nov 2004, verified at new URL 6 Aug 2009] http:/ / www.education.vic.gov.au/studentlearning/teachingprinciples/default.htm

Elliott, A. (2004). Cultural change needed to exploit ICT in schools. Information Age. [viewed 18 Oct 2006, verified at new URL 6 Aug 2009]

http: / / www.acs.org.au / index.cfm?action=show\&conID=200404161117204934

Elliott, D. J. (1995). Music matters: A new philosophy of music education. New York: Oxford University Press.

Gardner, H. (1983). Frames of mind. New York: Basic Books.

Gardner, H. (1991). The unschooled mind: How children think and how schools should teach. New York: Basic Books.

Herrington, J. \& Oliver, R. (2000). An instructional design framework for authentic learning environments. Educational Technology Research E Development, 48(3), 23-48.

Intelliware Australian (2006). SoundHouse Training Centres. Intelliware Sound House Articles [viewed 12 Oct 2006, verified 6 Aug 2009] http:// www.intelliware.com.au/Education/SoundHouse.aspx

Johansson, T. \& Miegel, F. (1992). Do the right thing: Lifestyle and identity in contemporary youth culture. Stockholm: Almquist \& Wiksell.

Kearney, M. \& Schuck, S. (2006). Spotlight on authentic learning: Student developed digital video projects. Australasian Journal of Educational Technology, 22(2), 189-208. http:/ / www.ascilite.org.au/ajet/ajet22/kearney1.html 
Lave, J. (1988). Cognition in practice: Mind, mathematics and culture in everyday life. Cambridge, MA: Cambridge University Press.

Marra, T. (2004). Authentic learning. University of Michigan. [viewed 1 July 2005, verified 6 Aug 2009] http:/ / www-personal.umich.edu/ tmarra/authenticity/authen.html

MCEETYA/MCVTE (2008). Communiqué Joint MCEETYA/MCVTE Meeting, 17 April. [viewed 21 May 2008, verified at new URL 6 Aug 2009] http: / / mediacentre.dewr.gov.au/ mediacentre/ AllReleases / 2008/ April/Joint+Ministerial+Communiqué.htm

Piaget, J. (1954). The construction of reality in the child. New York: Basic Books.

Piaget, J. (1974). To understand is to invent: The future of education. New York: Grossman.

Remier, B. (1995). Youth and modern lifestyles. In J. Fornäs \& G. Bolin (Eds), Youth culture in late modernity. London: Sage Publications.

Swanwick, K. (1968). Popular music and the teacher. UK: Pergamon Press.

Teaching with Technology Initiative (2003). TWT: Authentic Learning Approaches. North Dakota Teaching with Technology Initiative. [viewed 1 July 2004, verified 6 Aug 2009] http: / / www.ndtwt.org/Blackboard/P2SST2/ authenticlearning.htm

The School Charter (2006). The School Charter 2002-2004, updated 2006. [viewed 5 Sep 2006, URL withheld for privacy reasons]

The School Website (2006). The School Website. [viewed 5 Sep 2006, URL withheld for privacy reasons]

Vella, R. \& Arthurs, A. (2000). Musical environments. Sydney: Currency Press.

Vella, R. \& Arthurs, A. (2003). Sounds in space, sounds in time. London: Boosey \& Hawkes.

Victorian Government (2000). Skills $x$ knowledge $=$ growth: A statement from the Victorian Government on ICT skills. [viewed 18 Oct 2006, verified at new URL 6 Aug 2009] http:/ / www.mmv.vic.gov.au / Assets /614/1/SkillsxKnowledgeGrowth.pdf

Victorian Government (2007). Victorian Essential Learning Standards (VELS). Victorian Curriculum and Assessment Authority. [verified 8 Aug 2009] http:/ / vels.vcaa.vic.edu.au/

Vulliamy, G. \& Lee, E. (1980). Pop music in schools. New edition. Cambridge: Cambridge University Press.

Dr Renée Crawford

Department of Education

Monash University, Clayton, Australia

Email: crawfy12@aol.com 